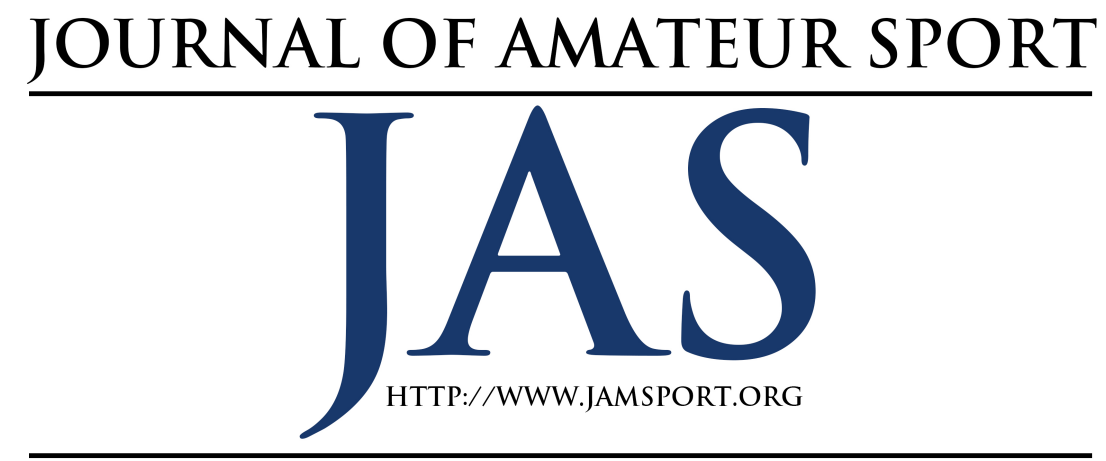

\title{
Examining Social Media Adoption and Change to the Stakeholder Communication Paradigm in Not-For- Profit Sport Organizations
}

\author{
Michael L. Naraine ${ }^{1}$ \\ Milena M. Parent ${ }^{2}$ \\ ${ }^{1}$ Deakin University \\ ${ }^{2}$ University of Ottawa and Norwegian School of Sport Sciences
}

\begin{abstract}
The purpose of this study was to examine social media adoption within not-forprofit sport organizations to illuminate the impetus for change, the type of change undertaken, and change resistance. Using a contextualist approach depicting the external and internal forces as well as the change process, semi-structured interviews were conducted with ten Canadian national sport organizations (NSOs) representing varying degrees of social media presence. The findings suggest that, although social media is espoused as a radical, transformational vehicle, NSOs have only made incremental adjustments to their stakeholder communication and have situated social media within their extant organizational condition due to capacity constraints and resistance from staff and reticent stakeholders. Adopting social media in light of limited organizational capacity thus diminishes the utility of the communications tool. Theoretical and practical implications include how to improve social mediarelated capacity and the importance of continuing the social media and sport domain's organizational theory agenda.
\end{abstract}

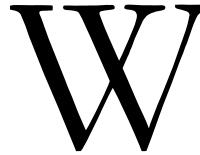

ith fluctuations in human resources, new programs and services developed and offered, and innovations in organizational design archetypes (to name a few), sport organizations are subject to change decisions affecting their routines and operations (Slack \& Parent, 2006). Sport organizations may desire or anticipate change, or have it simply thrust upon them due to internal or external pressures (cf. Amis, Slack, \& Hinings, 2004a; Kikulis, Slack, \& Hinings, 1995). Change is also thought to ensure sustainability in highly competitive marketplaces, although organizational inertia and stability in 
routines and practices can also provide optimal outcomes (Yi, Knudsen, \& Becker, 2016). With technological innovations and strategies gaining notoriety (cf. Caza, 2000), examining change to structures, processes, and/or mechanisms is important for the effective management of sport organizations (Cunningham, 2002).

One of the more recent technological innovations to emanate and subject sport organizations, especially those in the notfor-profit sector, to change has been the emergence of social media. These organizations, including national sport organizations (NSOs), have identified the importance of social media and have begun to develop and maintain social platforms (e.g., Abeza \& O'Reilly, 2014; Thompson, Martin, Gee, \& Eagleman, 2014). The adoption of social media as a stakeholder communication tool is of particular interest given their many challenges (cf. Misener \& Doherty, 2009), including a lack of exposure by traditional media sources (cf. Eagleman, 2013). Indeed, with a specific focus on NSOs, scholars have also noted an inability to diversify the range of content published on social media, succumbing to coercive, mimetic, and normative pressures (e.g., Naraine \& Parent, 2016). This is a particularly unique approach given the variance amongst social media usage by forprofit sport organizations (cf. Armstrong, Delia, \& Giardina, 2016; Pronschinske, Groza, \& Walker, 2012; Wang \& Zhou, 2015). Moreover, it remains unclear why NSOs (specifically) would choose to adopt social media and change the means by which they communicate with stakeholders given previous attempts to communicate and enhance stakeholder relationships online (i.e., using the World Wide Web) do not appear to have been fully realized (cf. Girginov, Taks, Boucher, Martyn, Holman, \& Dixon, 2009).

Thus, the purpose of this study was to examine social media adoption and change to stakeholder communication within the context of NSOs. Specifically, this study illuminates the overall impetus for change, the type of change undertaken (i.e., radical or convergent, evolutionary or revolutionary), and any (if at all) resistance to the change (given change is often difficult to achieve, as per Skinner, Stewart, \& Edwards, 1999). Although a collection of scholarship exists pertaining to change and sport organizations (e.g., Legg, Snelgrove, \& Wood, 2016; O’Brien \& Slack, 2004; Welty Peachey \& Bruening, 2011), there remains a dearth of understanding reflecting and relating to contemporary technological advancements in online communication (e.g., social media) and change to sport organizations. Understanding the nexus between social media and organizational change in NSOs is relevant given the influence these organizations typically have on sport systems (particularly in terms of long-term athlete development), and the aforementioned constraint on resources often found within these organizations.

To address this study's purpose, the contextualist approach to organizational change was employed as the theoretical framework. Initially conceptualized by Pettigrew (1987), the contextualist approach is composed of three primary dimensions: content, context, and process. Here, content (not to be confused with social media content) refers to what aspect of organizational change is taking place (e.g., 
products, structure, technology). Context refers to both the environmental and intraorganizational elements influencing the change process, revealing why change occurred. Finally, the "process" elements reveal insights from the change to depict how the change manifested in the organization. Although there are various perspectives on organizational change, including resource dependence (e.g., Pfeffer \& Salancik, 1978), life-cycle approach (e.g., Kimberly, 1980) and even Cunningham's (2002) model incorporating multiple dimensions of organizational change, the emphasis on the interrelationship between environment, internal structure, and human agency in depicting organizational change underscores the suitability of the contextualist approach for the present study. Simply put, the contextualist approach marries both the internal, external, and circumstantial factors which explain change processes. In doing so, this undertaking occupies a unique space within the extant literature, adhering to Filo, Lock, and Karg's (2015) call to advance social media and sport research using organizational theory frameworks. Moreover, the study provides important implications for practitioners in similar circumstances an opportunity to reflect upon how social media adoption occurs, the degree to which social media may change organizational actions, and the type of resistance that may be experienced as a result of the adoption process.

\section{Review of Literature and Theoretical Framework}

In this section, we provide an overview of the organizational change literature, including the types of change and why change is resisted, and the theoretical framework of interest, the contextualist approach, along with identifying the study's specific research questions. However, we preface this section with a brief review of the pertinent literature on social media and sport organizations.

Social media presents sport

organizations an additional avenue by which to connect to their publics online in a synchronous and asynchronous manner (Williams \& Chinn, 2010). For some organizations, this has enabled additional marketing ploys to develop, allowing for greater relationship building to occur (e.g., Hopkins, 2013; McCarthy, Rowley, Ashworth, \& Pioch, 2014; Waters, Burke, Jackson, \& Buning, 2011). However, others have viewed social media as a strategic communication tool, downplaying its abilities to leverage and activate sponsorships (Eagleman, 2013). This can be perceived as a potential flaw or inability to utilize these platforms to their full potential, particularly given the desire of stakeholders to want to consume and engage with organizations via social media (cf. Mahan, 2011). In fact, Gibbs, O'Reilly, and Brunette (2014) revealed fans of sport organizations not only seek information from social media, but desire promotional and interactive content. Part of the rationale for this desire stems back to the passion and camaraderie social media provides to this stakeholder group (Stavros, Meng, Westberg, \& Farelly, 2014). Nevertheless, there remains a significant appetite for social media content from sport organizations by its stakeholders (e.g., fans). 
The desire to consume social media and sport content has also led to an evolution in how content is presented. As Armstrong et al. (2016) found, organizations are introducing an animated, earnest persona to interact with fans, as well as competing sport organizations. Yet, concurrently, sport organizations like NSOs remain reticent to evolve their social media strategy to this extent or even simply to build stronger relationships (Abeza \& O'Reilly, 2014). This inability to adjust their strategic use of social media to align with competitors and others in their operational environment raises questions about why social media has been adopted altogether, leading to the purpose of the present study.

\section{Organizational Change}

Organizations are often subject to environmental disturbances and internal influences which stimulate change. Even if a so-called comfortable level of stability where comfort level is defined by the organization itself - is achieved and the organization has enacted a course of inertia, rapid changes in the organization's environment (e.g., technological innovations) may force the adoption of change (Slack \& Parent, 2006). In some cases, the external turbulence is attributable to political (e.g., Girginov \& Sandanski, 2008; Zakus \& Skinner, 2008) or social (e.g., Skirstad, 2009; Stronach \& Adair, 2009) stimulants. From an internal perspective, change may manifest itself as a result of an anticipated need to change to remain competitive and make the organization more efficient (Slack \& Parent, 2006). Irrespective of where the pressures of change originate, organizations still retain the ability to moderate the impact of change processes (e.g., products/services, technology, human resources). Greenwood and Hinings (1996) denoted two types of organizational change: radical and convergent. Radical change refers to major, transformational change which significantly alters the organization's operations, while convergent changes are slight, minor modifications to existing practices and routines. In the context of sport management, scholarship has focused primarily on radical change (e.g., Amis, Slack, Hinings, 2004b; Legg et al., 2016), though both types of change are difficult for organizations to manage (cf. Skinner et al., 1999).

Resistance to change. Part of the explanation for change being difficult to manage is the resistance organizations encounter. For Jaffe, Scott, and Tobe (1994), resistance is linked with the concept of denial, as agents exhibit a lack of trust and belief that change is necessary. As a result, employees may withhold their participation in the process, exhibit defensive behavior about the change, or even go so far as to persuade managers and other staff not to support the change. As Isabella (1990) suggested in her analysis, even in the aftermath of a change, pessimism about the change may persist. In such circumstances, staff may actively voice their displeasure or distrust of the adoption. Resisting change is not solely attributable to distrust however; agents may disagree with change based upon their own self-interest, differing assessments of change consequences, and the costs associated with enacting change (Slack \& Parent, 2006). When change occurs, there is the potential 
for some agents within the organization to lose resources, prestige, or professional competence; opponents of change are selfinterested and looking to preserve the power they have within the current organizational dynamic (Ybema, Thomas, \& Hardy, 2016). Beyond the intrinsic motivations to resist, agents may also worry about the unintended consequences of change. For instance, an organization adopting a new service or structure may be restricted from future changes as a result of expended resources, poor results, or simply fatigue (cf. Burgelman, 1991). As a result, while change in itself is not necessarily challenged by certain staff, the possibility of change may be problematic and challenge an organization's ability to adapt should modifications be required. Finally, individuals or groups within the organization may perceive the adoption as an inefficient use of the organization's (limited) resources (cf. Hannan \& Freeman, 1984; Suddaby \& Foster, 2016). Regardless of the type of resistance, managers may reevaluate, pivot, and/or choose not to enact the proposed action based upon the resistance they receive (Slack \& Parent, 2006).

\section{Evolutionary and revolutionary}

change. Given the threat change may bring to reliable, predictable operations (cf. Miller, Greenwood, \& Hinings, 1997), the various types of change resistance may also instigate organizations to seek inertia, providing stability to their present form and processes (Yi et al., 2016). This is especially true of older and larger organizations which tend to have well-established hierarchies, policies, and routines considered normative operations (Shimizu \& Hitt, 2005).
However, resisting potential changes to the dominant organizational condition is not always possible, especially when environmental trends dictate organizations align themselves accordingly (Boeker, 1997).

With the prospect of change, but a desire to maintaining stability, organizations may opt for evolutionary change. These incremental adjustments to the organization's routines allow change to be adopted, but mitigate possible incongruence (Tushman \& O'Reilly, 1996). Similar to the concept of convergent change, evolutionary changes are slow and continuous, enabling the organization to preserve the integrity of their design and structure, while incorporating minor changes. In essence, evolutionary change balances resistance with the need to change to reflect current trends. However, evolutionary change is not always possible, as environmental stimuli may warrant a larger, more impactful change. The resultant revolutionary changes are swift and often discontinuous, as the organization attempts to respond to major external developments. For instance, the institutionalized pressures to radically shift an organization's form from a simplistic to a professional bureaucratic structure to secure revenues would constitute a revolutionary change (cf. Slack \& Hinings, 1992).

Despite advances in organizational change scholarship, particularly those in a sport organization context (e.g., Legg et al., 2016; Zakus \& Skinner, 2008), our understanding of new communication and technological developments in these organizations remains weak. As Burgers (2016) noted, the implementation of new communication technologies and developments can be considered within an 
organizational change framework, particularly given these changes could be incremental (i.e., convergent, evolutionary) or immense (i.e., radical, revolutionary). As such, while scholars have discussed social media usage by sport organizations, especially those in the not-for-profit sector (e.g., Naraine \& Parent, 2016; Thompson et al., 2014), the context of adopting this change to their stakeholder communication remains unclear. By understanding the context in which this change has been adopted, the impetus and type of change can be illuminated, in addition to discussing the presence and basis for change resistance.

\section{Contextualist Approach}

Examining organizational change is difficult to explain without articulating the actions and processes which impact the adoption and implementation of change (Armenakis \& Bedeian, 1999; Pettigrew, Woodman, \& Cameron, 2001). Pettigrew (1987) conceptualized an approach that sought not just to illuminate what the change was, but also why change was occurring and how that change impacted routines and operations. The result (i.e., the contextualist approach to organizational change) was a set of three interconnected elements: content, context, and process. The first element refers to the areas and elements subjected to transformation. The content of change addresses what specifically has changed in an organization. Thus, content may refer to changes in human resources personnel, products and services offered or, in the case of the present study, technological advancements. The second element focuses on the why of change. The context of change explores environmental factors in which change is occurring. Pettigrew (1987) noted there are both internal and external contexts which explain the impetus for change. Within an organization (i.e., inner context), structure, culture, number of staff, types of leadership, and staff opinions can affect the change process. By contrast, the outer context refers to the broader circumstance (e.g., economic, social) affecting change. For instance, changes in best practices or turbulence in the operating environment may influence how an organization perceives its competitiveness and relevancy, and how the organization initiates the change process (e.g., Girginov \& Sandanski, 2008). The third and final element is concerned with the how of change. The process of change suggests actors, actions, and activities are key conduits in adopting change, as they can enable or inhibit the implementation of new or modified practices (Pettigrew et al., 2001).

Although Pettigrew's model has remained relatively unchanged (with regards to the interconnected elements), Dawson (2003) advanced a refined version of the framework. In this update, considerations were made to identify the type and scale of change (e.g., radical or convergent), while the process element incorporated the politics associated with change vis-à-vis resistance and conflict. Using the original approach with these refinements, the change literature is able to move beyond identifying the outcomes of adopting change towards why and how outcomes are shaped by contextual processes (cf. Wells, 2016). 
An important part of the contextualist approach to change is situating the notion of time. As Pettigrew et al. (2001) proposed, research on organizational change should be cognizant of the challenge of studying change processes longitudinally while depicting change as it happens concurrently. Although the former sentiment (i.e., change over time) adopts a chronological interpretation of change, the latter sentiment emphasizes the factors causing change in the interim. As such, applying a contextualist approach can be done in both considerations of time, which is helpful given the present circumstance where social media adoption has occurred in a short timeframe (cf. Eagleman, 2013; Thompson et al., 2014).

Although there are other ways to conceptualize change in organizations (e.g., Resource Dependency Theory, Life-Cycle Approach), the contextualist approach offers a logical, simple framework which has been supported by previous sport management research, particularly studies focusing on not-for-profit sport organizations in various geographical areas such as Canada (e.g., Thibault \& Babiak, 2005), Bulgaria (e.g., Girginov \& Sandanski, 2008), and Norway (e.g., Skirstad, 2009). Thibault and Babiak (2005) applied the approach to the Canadian sport system, documenting change from a bureaucratic to athlete-centered system longitudinally; Girginov and Sandanski (2008) examined Bulgarian NSOs over time to assess changes as result of political, economic, and social transformations the jurisdiction experienced moving from socialism to democratization; Skirstad (2009) utilized the contextualist approach to illuminate the gender imbalance of the Norwegian General Assembly of Sports over the course of three decades. However, it is Caza's (2000) work which sets a precedent to apply the contextualist approach in the present study. Caza's examination of technological change vis-àvis implementation of computer scoring, as well as a new method of ranking athletes, highlight key aspects of receptivity related to the context of change (e.g., effect of leadership, goals and priorities, environmental pressures). The ability of the contextualist approach to illuminate catalysts and stimulus for the adoption of technological innovations, in particular, is thus a useful guide for the present study.

Here, the contextualist approach is applied to examine how and why social media has been adopted by NSOs, but does so with a slight departure from past scholarship. Due to the rapid increase of social media usage in a short period of time, the present study is not concerned with change longitudinally; rather, it is concerned with the change experienced by NSOs as it has occurred. Second, while others have utilized the approach to document the content, context, and process of change (e.g., Girginov \& Sandanski, 2008; Thibault \& Babiak, 2005; Skirstad, 2009), the content of change in this circumstance is already known (i.e., social media adoption). As such, the contextualist framework is applied here to draw out the additional elements of change (i.e., context and process) to complement existing knowledge.

\section{Research Questions}

As the purpose of the study is to examine social media adoption and change to stakeholder communication within the 
context of NSOs, and being informed by the literature and framework noted above, the following research questions are advanced:

RQ1 - What internal and external forces have enabled social media adoption by NSOs?

RQ2a - What type of change was experienced as a result of social media adoption by NSOs? RQ2b - What resistance, if any, was experienced by NSOs in the adoption of social media?

\section{Method}

A qualitative design was implemented to uncover the experiences of individuals confronted with social media adoption within NSOs. Specifics on the participants, as well as data collection and data analysis techniques are provided below.

\section{Participants}

Drawing upon Naraine and Parent's (2016) work, a purposeful sample of eight Canadian NSOs were initially used. Although 61 NSOs in the Canadian sport landscape are currently funded by Sport Canada, the sample represented a balance of summer and winter sports and a range of social media presence (as defined by their followership - with the presumption being high followership would indicate larger, salient, and potentially more resourceful organizations). Preliminary contact was made with the same eight organizations via e-mail to assess availability and willingness to participate. Since two NSOs indicated they would not be participating, they were replaced with organizations with the same sport seasonality and similar social media presence (cf. Naraine \& Parent, 2016). Once data collection ensued, two additional interviews were deemed appropriate to confirm theoretical saturation achievement (cf. Charmaz, 2014), which resulted in a final sample of ten organizations (see Table 1). Participants representing these NSOs (with staff sizes between three and 30) consisted of actively employed personnel who organized, controlled, managed, and/or oversaw the social media operations within their organization. Based on these criteria, participants had various roles including chief executive officer $(n=2)$, director of marketing and communications $(n=4)$, communications and media relations manager $(n=2)$, and manager specifically in charge of digital content (e.g., websites and social media) $(\mathrm{n}=2)$. All participants were given pseudonyms to protect their identities while reporting the results to adhere to this study's ethics certificate guidelines. Moreover, additional consideration was given to protect participant identities, including not explicitly reporting job titles of participants, linking those titles to the selected organizations, and/or revealing the number of staff working at the organization during data collection.

\section{Data Collection}

The lead investigator conducted semistructured interviews with each NSO representative via phone conferencing given geographic distances. Interview questions (see Appendix A) were devised based upon the characteristics of the sample noted in Table 1 and previous literature on social media in sport (e.g., Armstrong et al., 2016; Gibbs et al., 2014; Stavros et al., 2014), 
including those specific to NSOs and social media (e.g., Abeza \& O'Reilly, 2014; Naraine \& Parent, 2016; Thompson et al., 2014). The contextualist approach framework was also utilized in the development of the interview guide. . Through careful probing, the lead investigator was able to provide an opportunity for respondents to reveal unique insights and unanticipated sentiments related to their organization and the adoption of social media (cf. Charmaz, 2014). Each interview lasted approximately 60 minutes; interview sessions were voicerecorded, transcribed (maintaining anonymity of respondents), and returned to participants for verification. Only two interviewees requested changes to their applicable transcripts, wishing to clarify some concepts or redact names of colleagues or perceived defamatory comments.

\section{Data Analysis}

Data were deductively coded using Pettigrew's (1987) three-pronged framework and the refinements made by Dawson (2003). The sorting of data fragments into deductive elements provided an initial opportunity to align the present findings with the specified research questions, adhering to the approach of others who utilized the contextualist approach (e.g., Skirstad, 2009). However, subsequent coding was performed inductively to reveal additional insights or concepts not necessarily fitting into the conceptual model but addressing the study's purpose and research questions, akin to Legg et al.'s (2016) procedure. To perform these actions, all data were imported and analyzed using the NVIVO 10 computer software program, which can facilitate data fragmentation and coding. Findings were discussed between the authors to ensure coherence.

\section{Findings}

Interviewee sentiments were grouped into the categories derived from the contextualist approach (i.e., outer context, inner context, and process), and organized based on the organization's social media presence (i.e., "high", "mid-high", "midlow", and "low") to elucidate similarities and differences in the change experience. The findings' implications regarding organizational change are presented in the discussion section.

\section{Outer Context}

NSOs' impetus to adopt social media seemed to emanate from the need to engage with stakeholders, specifically fans of the sport, members (e.g., athletes), and even sponsors (to a lesser extent), as well as maintain the guise of a credible, modern organization in a competitive operating environment.

In the case of the high social media presence organizations, both respondents communicated the need to adopt various social media platforms to engage their stakeholders, but with slight differences in who those stakeholders actually were. Change to their stakeholder communication was deemed necessary and attributable to the environmental shift away from traditional media by other organizations. Yet, for Curling Canada, there was also a distinct focus on connecting with fans as opposed to other stakeholder groups: 
I mean, it's rare that an organization doesn't have social media presence. I think it just is reflective of the demographics, and reflective of today's society. Traditional media, traditional ways of communicating are out the window. Cable television and newspapers just don't reach people the way that social media do, and that's the way the world has evolved.

[Organizations] want to get things done. They want to reach their fans. (Anthony, Curling Canada) When probed about wanting to "get things done" and reaching fans, Anthony explained his organization had "a very loyal fan base that love to engage on social media platforms," requiring Curling Canada to adopt a social presence to ensure those fans remained loyal and engaged. The other respondent in this grouping, Linda (Tennis Canada), expressed a similar response, indicating that adopting social media was "definitely just a reality" of the current environmental landscape: "I would think it was strange for sure if [organizations] weren't investing at all in the social space." However, Linda also indicated the expectation to adopt social media extended beyond fans to include teams and athletes, creating "a bit more personal connection" than traditional communication media can provide with those specific stakeholders.

The mid-high social media presence cohort also conveyed similar sentiments about the external context in which NSOs adopted social media, honing in on stakeholder expectations, as well as perceived success. Jade, a Canadian Freestyle Ski staff member, noted the "real responsibility that organizations have when it comes to social media" in that it serves as "the first point of contact for a lot of people in and outside the organization." In this sense, adopting social media within NSOs was deemed critical based upon stakeholders' expectations. Jade extended her thoughts about other organizations adopting social media, stating: "A lot of people and organizations define themselves and the success of their organization based on the number of followers they have...so I would question the credibility of an organization if they weren't on social media." In this respect, adopting social media moves beyond simply an expectation of stakeholders towards organizations being perceived as more credible and successful. Although he did not make a direct link with this idea, Jim (from Softball Canada) explained sponsors have contacted his organization to remain apprised of the growth and reach of their social media following. The recognition of stakeholder expectations beyond simply fans and athletes was also noted by Bill at Canada Snowboard: "I think everybody's engaging with so many different businesses now that I think it's almost a necessary evil that you have to have now in order to connect with your followers." Bill's characterization of social media as a widespread tool utilized in multiple industries supports the idea of NSOs being pressured into adopting new processes in order to maintain credibility with stakeholders and operate within the expected norms of a modern organization.

Organizations characterized as mid-low in their social media presence expressed similar environmental factors in their adoption of social media (e.g., stakeholder expectations), but downgraded the notion 
of perceived success. Carla, a Sail Canada staff member, commented hers and other organizations have "all come to realize that [social media] is not a fad, it's not going away. We need to keep up with the times." The notion that organizations adopt social media as a means to adhere to the status quo was also advanced by Carla: "I think we're just going with the flow." Similarly, Corey at Bobsleigh Canada, remarked: "Everyone knows it's there, everyone understands we need to be part of it. And I bet you could poll a lot of people out there that say they do social media for the sake of doing social media." Yet, although this opinion was shared by the respondents in this category, both Corey from Bobsleigh Canada and Andrew from Archery Canada indicated adopting social media was not a result of perceived credibility or organizational success, or even the expectation of funding partners. "Sport Canada really doesn't care how well you're communicating with your members," Andrew explained. "They're interested in how close you are to an Olympic medal." In essence, staff members representing organizations in the mid-low social media presence category acknowledged the adoption of social media as a basic component of operating in the current time period, but not a component that can overhaul how stakeholders perceive the organization.

The two respondents in the low social media presence cohort also offered similar remarks, citing the adoption of social media as an expectation. Terrence at Luge Canada commented: "I think it's expected now in society that there is that type of, you know, those types of platforms in place. It would look kind of funny if you didn't have it now." While Cassandra at Fencing Canada made a similar comment, she suggested there was an element of adoption as a marker of effectiveness: "[Not having social media] gives the perception that you're not with the times, you know you're not maybe as effective as you should be." While the two respondents agreed that adopting social media is an expectation, there was some division, as Cassandra advanced her attitude towards social media adoption and organizational effectiveness.

Coinciding with NSOs adopting social media because it is an expectation of their stakeholders (ranging from fans to sponsors depending on the respondent) is the idea of adoption of social media platforms as a means of connecting with a younger demographic. Across all ten organizations, respondents indicated adopting social media was attributable to its acceptance by younger individuals, particularly as a new generation of athletes begin to compete in their respective sport. As Carla put it: "If that's the way it's going with a younger demographic, we need to keep up with that and make sure that we're staying somewhat relevant."

\section{Inner Context}

Whereas the outer context revealed an environment in which NSOs are expected to adopt social media communication as a stakeholder-based normative behavior, preexisting communications infrastructure, limited capacity (i.e., human and financial resources), and NSOs' core focus were prominent internal factors impacting the adoption. 
Both respondents at Curling Canada and Tennis Canada explained that, despite their organization's standing amongst other Canadian NSOs, they, too, experienced capacity constraints. Anthony from Curling Canada put it very bluntly: "We don't have the money behind [social media]. Let's get that straight." Although Anthony estimated his organization had over 100 employees and interns, only four individuals were devoted towards the communications function, only one of whom was a full-time staff member, and tasked with media relations, website creation, and e-mails (among others). As such, contrary to their position as an organization with a high social media presence, social media adoption was added to Curling Canada's small, but functioning communications team. Linda at Tennis Canada also expressed similar capacity concerns: "Everyone's pretty stretched and it's a relatively new thing to be focusing on." In an organization similar in staff size and composition to Curling Canada, Linda explained Tennis Canada had already utilized digital properties (e.g., website, emails) as well as traditional communications activities (e.g., telephone calls, newsletters, face-to-face meetings) to interact with stakeholders and, thus, adopting social media for her organization was complimentary to the already established digital presence.

Softball Canada and Canada Snowboard provided similar experiences with capacity constraints, though Canadian Freestyle Ski has some slight deviations in their response. As Bill from Canada Snowboard explained: 'We're just trying to keep our heads above water. It's just getting the resources, the human resources to execute." Bill's comments were amplified when he mentioned there were roughly a dozen fulltime staff members within his organization. Similarly, Jim at Softball Canada indicated his organization only had one person charged with handling communications (out of eight reported staff members), indicative of a human resource shortfall. However, despite the deficiency in capacity, Jim noted it was important for his organization to focus on its task to communicate programs and information to athletes, fans, and provincial softball associations. In the case of Canadian Freestyle Ski, whose reported focus was elite athlete development and high-performance, there was no direct mention of a lack of financial or human resources. Indeed, the challenge for Jade and her colleagues was not the initial adoption of social media to communicate with stakeholders, but rather managing social platforms as they grow, evolve, and cause "bandwidth issues."

A lack of capacity was also evident amongst Sail Canada, Archery Canada, and Bobsleigh Canada. Within Sail Canada and its reported staff of eight, Carla acknowledged her organization was not alone in this experience: "I think we suffer very similar struggles that other NSOs have which are capacity issues. That's always been our struggle." With one person in her organization managing all communications aspects (e.g., e-mails, phone calls), it would appear unlikely to add additional communications tasks onto that individual. Yet, as Carla mentioned, adopting social media aligned with Sail Canada's values of communication and accountability, thereby explaining why such a change would occur. 
This was also the case for Archery Canada; Andrew noted his organization was committed to serving its stakeholders, and social media enabled such service despite minimal staff (i.e., two full-time, one parttime). For Bobsleigh Canada, driving interest and awareness of the sport and athletes was reported as the primary focus of the organization, and all messaging reflected this focus. Indeed, Corey commented: "The opportunities are endless, but it all comes down to a capacity issue and what are the priorities, and you've got to deal with the priorities first." As such, Corey acknowledged that adopting social media could help drive interest and awareness, but argued the lack of capacity had significant implications on the degree to which it was utilized.

Not dissimilar from the other groups, both Fencing Canada and Luge Canada espoused their limited organizational capacities for social media adoption. Cassandra revealed her organization was incredibly lean (i.e., two staff members) and did not boast a physical office, which had already placed a strain on Fencing Canada's operations. However, she also noted her organization was focused on serving its community (e.g., athletes, provincial associations) by "keeping people up to date." Nevertheless, when asked about adopting social media, Cassandra highlighted the lack of capacity ultimately affected her organization's ability to utilize it to a great extent. Terrence at Luge Canada communicated a similar sentiment, but went so far as to suggest the reality at some NSOs may be different than his organization's own experience: "I find a lot of the other NSOs probably have someone paid doing [social media]. Where us, we kind of try to do as much as we can, but there are certain things we can't, and [social media] would be one thing." With a reported staff of six individuals, Terrence commented his organization was "very rudimentary" and could not allocate financial resources towards social media. Although Luge Canada did have centralized communications with one person managing e-mails and website activities, social media was considered an afterthought as the focus was and would always be on highperformance success, as Terrence reported.

\section{Process (Politics of Change)}

In discussing social media adoption, two prominent themes emerged: the politics of communication (for Canadian NSOs) and resistance experienced, whether internal (i.e., from staff within organization) or external (i.e., from outside stakeholder groups).

There was a clear division in the responses between Curling Canada and Tennis Canada when it came to understanding the process of adopting social media. When raising the issue of language and content, Anthony mentioned adopting social media aided in promotional marketing and sharing multimedia, but the tool itself raised significant language concerns, specifically the tone and type of content and the issue of bilingualism.

We paint with a pretty broad brush. We're conditioned to the fact that we have corporate partners who need to be respected, and may not want to be associated with someone that pushes the envelope... posting out a couple of tweets about [an athlete] hitting on 
showgirls might not be something that the little old ladies in Saskatchewan would be down with. (Anthony, Curling Canada)

Indeed, it was suggested a professional tone was necessary to maintain organizational legitimacy amongst its stakeholders, specifically sponsors and older demographics who have demonstrated a hesitance towards adopting social media themselves. Translating Curling Canada content from English to French, an official language of Canada, was also reported to be problematic, as it took additional resources (e.g., money, time) for content to be translated and negated the expediency of using social media altogether. Conversely, Linda did not experience major resistance within the organization or from its stakeholders, but did note the difficulty in justifying a large social media presence without identifying the return on investment. Moreover, with two bilingual staff members working on social media based in Toronto and Montreal respectively, managing content in both official languages did not appear to pose a problem for Tennis Canada.

Striking a balance between English and French content was also reported to be an issue for Canadian Freestyle Ski, Softball Canada, and Canada Snowboard, while the latter two organizations also explicitly documented the internal resistance to adopting social media altogether. Jade at Canadian Freestyle Ski indicated bilingualism in all communication was paramount for her organization to ensure funding from government partners (e.g., Sport Canada) remained in place. Though her organization had French-language employees to populate content, she mentioned outsourcing of translation services created additional costs. At Softball Canada, Jim reported his organization was capable of handling the bilingualism issue, as the individual responsible for social media was bilingual, but did reveal a tendency to focus mainly on English language content, because the overwhelming majority of stakeholders were English first: "You can get lazy sometimes and put more in English and kind of ignore the French." Bill at Canada Snowboard summarized the bilingualism issue as it related to adopting social media:

Oh, it's a massive issue. It's something that, you know, we do have some obligation to with being a bilingual country, but also our - some of our funding is tied to making sure that we're communicating in both languages with athletes that are, you know, primarily French or bilingual. The struggle that we've found is investing in that and the return on it. You know we've done a lot of analytics, posting in French and then posting in English or vice versa, or posting in both languages, and I would say that probably $90-95 \%$ of our following is at least English first, if not English primary.

What exacerbates the bilingualism requirement is the organizational resistance these organizations incurred simultaneously. As Bill suggested, it remained a challenge to get staff within Canada Snowboard to consider social media as a worthwhile investment, as opposed to devoting resources towards high-performance objectives. Jim expanded on this point, 
indicating the resistance from organization staff came from a specific subset: "Older administrators don't seem to see the value in [social media]."

While Sail Canada's insight on the politics of social media adoption was similar to those of Canadian Freestyle Ski (e.g., having a bilingual social media curator, limited organizational resistance), both Archery Canada and Bobsleigh Canada depicted a struggle with the bilingualism and resistance to adopting social media. Andrew claimed Archery Canada worked diligently to have a balance of English and French posts, but the delay in French translation meant refraining from communicating for up to 24 hours in some cases, plus the high costs for such a turnaround. At Bobsleigh Canada, Corey did not choose to divulge the extent to which his organization maintained a bilingual social media presence. However, he did offer a comment pertaining to the resistance in adopting social media; within the Bobsleigh Canada organization, there was a recognition that athlete success was the most important priority and resources should be devoted to hiring coaches, trainers, and associated activities. Andrew agreed with this sentiment, but also reflected upon Archery Canada's stakeholders: "We have a little bit older, different generation who are very reticent to move onto [social media]." As such, Andrew believed it would be an inefficient use of his organization's resources to expand their social media presence when their stakeholders would not be utilizing those platforms.

The hesitance in committing significant resources towards social media as a result of internal or external resistance and the issue of bilingualism was also expressed by Fencing Canada and Luge Canada. Cassandra from Fencing Canada communicated the presence of "an age drop off," whereby certain age brackets would not be engaged with the organization on social media platforms. Beyond this resistance, she also expressed concerns regarding bilingual communication: "We have a strategy to try and post in both official languages, but we don't always succeed in that. [Sport Canada] audits us for bilingualism; it's a big issue." This notion of a communications audit from a significant funding source illustrates Fencing Canada's reservations regarding social media adoption. Along a similar vein, Terrence at Luge Canada revealed his organization's cynical view of social media: "I don't think anyone sees the importance of it. We're at a stalemate, where we've got enough to do with what we're doing right now, and there's no argument in place by anybody to spend more." He expanded upon this point further through his $\$ 30,000$ example: if Luge Canada were to receive $\$ 30,000$, and had the option of hiring a high-performance coach or a dedicated social media curator, the former would be chosen, as it would contribute directly to athlete success, consequently increasing funding. As such, although the organization adopted social media, Terrence concluded it was an afterthought relative to Luge Canada's other priorities.

\section{Discussion}

The impetus to adopt social media within NSOs appears to be predominantly motivated by stakeholders' expectations and by pre-existing communications 
infrastructure. In the current business environment in which these organizations operate, incorporating social media is necessary to remain competitive given the recent shift in digital technologies (Kaplan \& Haenlien, 2010). Moreover, the acknowledgement by respondents in the present study that their stakeholders expected organizations to have a social media presence reflects this trend. This finding explains why many of these organizations succumbed to coercive, mimetic, and normative pressures with their social media presence (see Naraine \& Parent, 2016). The logic of adopting social media in order to remain competitive is exacerbated by the perceived legitimacy and relevancy such actions are believed to offer. As explained in the findings, there was a tendency for some to attribute the integration of social media into their organization as an act of demonstrating modernity. The evidence provided also depicted the decision to adopt a social media presence as being affected by the current process of communication with internal and external parties.

Communication is important for these organizations to demonstrate accountability and transparency (thus securing funding from government partners), and NSOs have shown a willingness to develop new platforms, especially in a digital setting, to conduct these activities (cf. Girginov et al., 2009). Thus, it is not unsurprising that a new communications tool such as social media would be adopted by the organizations under study; as new platforms emerge that foster enhanced communication (e.g., instantaneous, expedited), NSOs attempt to develop their presence and integrate the additional tasks alongside other ongoing communication activities (e.g., e-mails, telephone calls, newsletters).

Although the motivation to adopt social media would indicate an increased importance of adopting new communication approaches (given stakeholders' expectation) and few challenges (given the integration with other communications activities), the organizational capacity issue helps explain NSOs' subdued social media presence. It should come as no surprise that capacity is cited as having a significant impact on these organizations' ability to develop and maintain a social media presence; this issue has been previously identified as a key factor in the operations of sport organizations (e.g., Amis et al., 2004a; Misener \& Doherty, 2009), and the findings here suggest capacity constraints affect the operationalization of social media as well. Specifically, the lack of human and financial resources hinders the ability to offer a diverse presence (on multiple platforms) with dynamic, engaging content as sport development-expenses are prioritized over social media-related expenses. Whereas a for-profit sport organization may have the ability to expend resources to develop a presence on a variety of platforms including incorporating new, emerging sites, not-forprofit sport organizations are cognizant of their inability to offer a high-quality social media presence to communicate to their stakeholders. What is perhaps most remarkable about this finding was that the lack of capacity drew a consensus across the four groups of social media presence (i.e., high, mid-high, mid-low, and low). Despite 
the varying degree of commercial viability and professionalization amongst this cohort (cf. Girginov et al., 2009), all NSOs seem subject to similar resource constraints which inhibit their adoption of change. Indeed, the findings suggest capacity limitations can stymie the extent to which social media is adopted and advanced within an organization.

Along this vein, the challenge of balancing bilingual communication and resistance from staff members and stakeholder groups (e.g., older constituents) also impacted how NSOs adopt social media. Although these organizations are accustomed to the bilingual communications paradigm existing within the Canadian landscape, there remains an inability for these organizations to reconcile the expedited nature of social media communication (e.g., populating and translating content for English and French accounts in a timely fashion). The findings allude to the capacity issue once more, with few bilingual staff members tasked with communication, and/or an inadequate budget for translation. Concurrently, NSOs are faced with resistance from internal staff members looming over their adoption of this new form of communication. Despite the espoused benefits NSOs may receive from adopting social media, including alleviating a lack of traditional media coverage and increased marketing promotions (Eagleman, 2013), some within these organizations do not appear to ascribe to these espoused benefits, and contend that such communication merely diverts resources away from core objectives (e.g., elite athlete development) (cf. Hannan \& Freeman, 1984). Indeed, there exists a lack of recognition of the potential for increased partnerships and unique sponsorship activations that could yield additional revenue to apply to athlete development. The resistance within NSOs is also fueled by the perceived unwillingness of older demographics to communicate on these new platforms. As such, social media can become a chore with a limited function. Social media is not perceived as a resource to increase the organization's capacity; rather, it is used to expedite communication with certain stakeholders. This reasoning also helps explain why there was little variance between the messages conveyed by these organizations on social media (cf. Naraine \& Parent, 2016). Based on this premise, administrators are content to deploy limited resources towards their social media presence, and do so while maintaining a level of doubt about the potential benefits of such communication (cf. Isabella, 1990).

Considering the application of Pettigrew's (1987) contextual approach in this circumstance, the findings not only uncover why and how social media has been adopted as an additional medium to communicate with stakeholders, but underscores social media as an evolutionary, convergent change mechanism, rather than a source of radical, revolutionary change for NSOs. The external forces pressuring NSOs to adopt social media, the resistance begot from reticent staff and older stakeholders, and the limited organizational capacity were not enough to preserve organizational stability (cf. Boeker, 1997). However, the findings depict social media adoption as an incremental shift, incorporated into the existing communications paradigm, and 
mitigating the potential for incongruence with organizational stability (cf. Tushman \& O'Reilly, 1996). Social media adoption can also be considered as a type of convergent change. Developing and sustaining a social media presence has not affected major, transformational change in these organizations (Greenwood \& Hinings, 1996); rather, change offers a slight, minor modification to the organization's communication with its stakeholders. This is an important consideration given the degree to which social media is championed as a paradigm shifting vehicle (e.g., Kaplan \& Haenlein, 2010; Waters, Burke, Jackson, \& Buning, 2010). Although the emergence of social media has shifted NSOs away from a state of inertia, its adoption remains a minor change with minimal impact on the day-to-day operations. Given the above, we posit that the degree to which social media adoption can affect change is mediated by capacity and resistance (from stakeholders and staff members). This proposition should, however, be tested in other settings.

\section{Implications and Contributions}

From a practical standpoint, the findings provide new insight that may help managers and staff within similar organizational contexts. More precisely, understanding why and how social media has been adopted can enable other not-forprofit sport organizations who have hesitated or delayed this change in communicating with their stakeholders. Practitioners should be conscious of the challenge of, and resistance to, adopting social media, namely negotiating between multilingual content and clearly communicating to staff the intended purpose and goals of utilizing this vehicle. Reflecting upon the results, not-for-profit sport organizations in a similar linguistic circumstance may wish to consider making multilingualism imperative for tasks associated with social media (and traditional media) communication with stakeholders. Whether in the form of providing language training for communications staff or hiring bilingual staff, organizations can reduce the capacity strain (e.g., costs associated with translation). While the Canada's bilingual circumstance may seem unique, practitioners in other jurisdictions may still wish to reflect upon how their organization incorporates official or de facto second (or more) languages, reducing the potential alienation of stakeholder groups. For instance, organizations in the United States should be concerned with English and Spanish language stakeholders, Belgium with Dutch and French, and perhaps Germany with its growing Turkish contingent (to name a few). Ensuring staff understand how the adoption of social media can benefit the organization is also important to ensure resistance does not lead to change fatigue (cf. Burgelman, 1991) or belief their position is in jeopardy (cf. Ybema et al., 2016), the latter especially with older and/or unilingual employees.

For scholars, the findings presented here add to the current, fluid understanding of social media within sport, particularly in not-for-profit sport organizations. With social media continuing to gain prominence, it is plausible more organizations will continue to adopt this method of communication. However, the findings also suggest it is likely this change will be minor and not radically shift an organization's 
condition. This notion has important implications within the social media and sport domain, including helping to explain how not-for-profit sport organizations come to exhibit isomorphic tendencies in their social media presence (cf. Naraine \& Parent, 2016). The reported impact capacity has on the adoption of social media also serves to advance the theoretical foundation of social media in sport. As social media is espoused as a tool with significant abilities (e.g., Eagleman, 2013; Kaplan \& Haenlein, 2010; Waters et al., 2010), it is critical to recognize the influence capacity can have on its utility. In the present circumstance, low capacity resulted in diminished utility once social media was adopted. While this concept is simple and straightforward, it raises an important consideration for scholars: the inverse (i.e., high capacity resulting in increased utility) may not necessarily be true. Given the elite athlete development focus by these types of sport organizations, it is unclear whether an organization with significant capacity would deploy more resources to their social media presence. With calls to continue examining social media in sport using organizational and strategic management models (cf. Filo et al., 2015), highlighting how high versus low capacity impacts the adoption, utilization, and maintenance of a social media presence can reveal additional insights and complement the knowledge garnered in the present study.

\section{Limitations}

The present study was subjected to (de)limitations, much of which stemmed from the methodological approach. First, while this study focused on not-for-profit sport organizations, the sample was drawn from one jurisdiction (i.e., Canada), which affects the generalizability of the results. However, some of the results can still be adapted in other contexts (e.g., balancing multilingualism). Second, the findings were limited to the responses of the individuals representing the sampled NSOs; responses were assumed to be an accurate representation of the experience of their respective organizations, but respondents may have chosen to withhold information or provided an account differing from those communicated by their colleagues. Finally, the context of adopting social media was limited to one data source (i.e., interviews), and it is unknown whether data ascertained from additional sources (e.g., meeting documents, websites, e-mail exchanges) would have yielded new information.

\section{Future Directions}

This study offers a basis on which future research may continue to build. Scholars should continue pursuing qualitative approaches to enhance the social media and sport research agenda, including uncovering the experiences of practitioners dealing with the phenomena. However, future studies may consider shifting the context from North America (e.g., Canada, United States) towards the Global South (e.g., India, China). Given the capacity issues cited in this study, understanding how change to stakeholder communication is adopted (or not) from these perspectives can enhance the findings of the current study. Scholars may also wish to reflect upon how stakeholders perceive the adoption of social media in a given organization; the present study isolated 
focal organizations adopting the change, but future studies may wish to explore how stakeholders react to the change process. Finally, although social media is still emerging and evolving, researchers may reflect upon this change to stakeholder communication once the process has matured, taking a longitudinal approach and juxtaposing the results with those found in the present study.

\section{Conclusion}

Although social media is lauded for its ability to help organizations connect with stakeholders instantaneously without spatial limitations, it does not seem to have triggered the immense change previously postulated (cf. Kaplan \& Haenlein, 2010). Using Pettigrew's (1987) contextualist approach, this study's findings note adopting social media results in an evolutionary, convergent change to the stakeholder communication paradigm within not-for-profit sport organizations. The findings reinforce the notion of organizations changing for change's sake (i.e., to meet stakeholder expectations and maintain relevancy/legitimacy) instead of choosing inertia due to their limited capacity. Moreover, as new innovations and advancements occur in the operating environments, not-for-profit sport organizations are likely to incorporate this change without maximizing its utility. 


\section{References}

Abeza, G., \& O'Reilly, N. (2014). Social media platforms' use in building stakeholder relationships. Journal of Applied Sport Management, 6, 103-126.

Amis, J., Slack, T., \& Hinings, C. R. (2004a). Strategic change and the role of interests, power, and organizational capacity. Journal of Sport Management, 18, 158-198.

Amis, J., Slack, T., \& Hinings, C. R. (2004b). The pace, sequence, and linearity of radical change. Academy of Management Journal, 47, 15-39. doi: $10.2307 / 20159558$

Armenakis, A. A., \& Bedeian, A. G. (1999). Organizational change: A review of theory and research in the 1990s. Journal of Management, 25, 293-315. doi: 10.1177/014920639902500303

Armstrong, C. G., Delia, E. B., \& Giardina, M. D. (2016). Embracing the social in social media: An analysis of the social media marketing strategies of the Los Angeles Kings. Communication \& Sport, 4, 145-165. doi: $10.1177 / 2167479514532914$

Boeker, W. (1997). Strategic change: The influence of managerial characteristics and organizational growth. Academy of Management Journal, 40, 152-170. doi: 10.2307/257024

Burgelman, R. A. (1991). Intraorganizaitonal ecology of strategy making and organizational adaptation: Theory and field research. Organization Science, 2, 239-262. doi: 10.1287/orsc.2.3.239

Burgers, C. (2016). Conceptualizing change in communication through metaphor. Journal of Communication, 66, 250-265. doi: $10.1111 /$ jcom.12211
Caza, A. (2000). Context receptivity: Innovation in an amateur sport organization. Journal of Sport Management, 14, 227-242.

Charmaz, K. (2014). Constructing grounded theory (2nd ed.). London, England: SAGE.

Cunningham, G. B. (2002). Removing the blinders: Toward an integrative model of organizational change in sport and physical activity. Quest, 54, 276-291. doi: 10.1080/00336297.2002.104917779

Dawson, P. (2003). Reshaping change: A processual perspective. London, England: Routledge.

Eagleman, A. N. (2013). Acceptance, motivations, and usage of social media as a marketing communications tool amongst employees of sport national governing bodies. Sport Management Review, 16, 488-497. doi: 10.1016/j.smr.2013.03.004

Filo, K., Lock, D., \& Karg, A. (2015). Sport and social media research: A review. Sport Management Review, 18, 166-181. doi: 10.1016/j.smr.2014.11.001

Gibbs, C., O'Reilly, N., \& Brunette, M. (2014). Professional team sport and Twitter: Gratifications sought and obtained by followers. International Journal of Sport Communication, 7, 188213. doi: 10.1123/IJSC.2014-0005

Girginov, V., \& Sandanski, I. (2008). Understanding the changing nature of sports organisations in transforming societies. Sport Management Review, 11, 21-50. doi: 10.1016/S1441-3523(08)70102-5 
Girginov, V., Taks, M., Boucher, B., Martyn, S., Holman, M., \& Dixon, J. (2009). Canadian national sport organizations' use of the web for relationship marketing in promoting sport participation. International Journal of Sport Communication, 2, 164-184.

Greenwood, R., \& Hinings, C. R. (1996). Understanding radical organizational change: Bringing together the old and the new institutionalism. Academy of Management Review, 21, 1022-1054.

Hannan, M. T., \& Freeman, J. (1984). Structural inertia and organizational change. American Sociological Review, 49, 149-164.

Hopkins, J. L. (2013). Engaging Australian rules football fans with social media: A case study. International Journal of Sport Management and Marketing, 13, 104-121. doi: 10.1504/IJSMM.3013.055197

Isabella, L. A. (1990). Evolving interpretations as a change unfolds: How managers construe key organizational events. Academy of Management Journal, 33, 7-41. doi: $10.2307 / 256350$

Jaffe, D., Scott, C., \& Tobe, G. (1994). Rekindling commitment: How to revitalize yourself, your work, and your organization. San Francisco, CA: Jossey-Bass.

Kaplan, A. M., \& Haenlein, M. (2010). Users of the world, unite! The challenges and opportunities of social media. Business Horizons, 53, 59-68. doi: 10.1016/j.bushor.2009.09.003

Kikulis, L. M., Slack, T., \& Hinings, C. R. (1995). Sector-specific patterns of organizational design change. Journal of Management Studies, 32, 67-100. doi: 10.1111/j.1467-6486.1995.tb00646.x Kimberly, J. R. (1980). The life cycle analogy and the study of organizations: Introduction. In J. R. Kimberly, \& R. H. Miles (Eds.), The organizational life cycle (pp. 1-14). San Francisco, CA: Jossey-Bass.

Legg, J., Snelgrove, R., \& Wood, L. (2016). Modifying tradition: Examining organizational change in youth sport. Journal of Sport Management, 30, 369381. doi: 10.1123 /jsm.2015-0075

Mahan III, J. E. (2011). Examining the predictors of consumer responses to sport marketing via digital social media. International Journal of Sport Management and Marketing, 9, 254-267. doi: 10.1504/IJSMM.2011.041575

Miller, D., Greenwood, R., \& Hinings, B. (1997). Creative chaos versus munificent momentum: The schism between normative and academic views of organizational change. Journal of Management, 6, 71-78. doi: 10.1177/105649269761014

McCarthy, J., Rowley, J., Ashworth, C. J., \& Pioch, E. (2014). Managing brand presence through social media: The case of UK football clubs. Internet Research, 24, 181-204. doi: 10.1108/IntR-08-2012-0154

Misener, K., \& Doherty, A. (2009). A case study of organizational capacity in nonprofit community sport. Journal of Sport Management, 23, 457-482.

Naraine, M. L., \& Parent, M. M. (2016). "Birds of the same feather:" An institutional approach to Canadian national sport organizations' social media usage. International Journal of 
Sport Communication, 9, 140-162. doi: 10.1123/IJSC.2016-0010

O'Brien, D., \& Slack, T. (2004). The emergence of a professional logic in English Rugby Union: The role of isomorphic and diffusion processes. Journal of Sport Management, 18, 13-39.

Pettigrew, A. M. (1987). Context and action in the transformation of the firm. Journal of Management Studies, 24, 649668. doi: $10.1111 /$ j.14676486.1987.tb00467.x

Pettigrew, A.M., Woodman, R. W., \& Cameron, K. S. (2001). Studying organizational change and development: Challenges for future research. Academy of Management Journal, 44, 697-713. doi: $10.2307 / 3069411$

Pfeffer, J., \& Salancik, G. (1978). The external control of organizations: A resourcedependence perspective. New York, NY: Harper \& Row.

Pronschinske, M., Groza, M. D., \& Walker, M. (2012). Attracting Facebook 'fans': The importance of authenticity and engagement as a social networking strategy for professional sport teams. Sport Marketing Quarterly, 21,

Shimizu, K., \& Hitt, M. A. (2005). What constrains or facilitates divestitures of formerly acquired firms? The effects of organizational inertia. Journal of Management, 31, 50-72. doi: 10.1177/0149206304271381

Skinner, J., Stewart, B., \& Edwards, E. (1999). Amateurism to professionalism: Modelling organisational change in sporting organisations. Sport Management
Review, 2, 173-192. doi: 10.1016/S1441-3523(99)70095-1

Skirstad, B. (2009). Gender policy and organizational change: A contextual approach. Sport Management Review, 12, 202-216. doi: 10.1016/j.smr.2009.03.003

Suddaby, R., \& Foster, W. M. (2016). History and organizational change. Journal of Management (advance online publication). doi: 10.1177/0149206316675031

Slack, T., \& Hinings, C. R. (1992). Understanding change in national sport organizations: An integration of theoretical perspectives. Journal of Sport Management, 6, 114-132.

Slack, T., \& Parent, M. M. (2006). Understanding sport organizations: The application of organization theory (2nd ed.). Champaign, IL: Human Kinetics.

Stavros, C., Meng, M. D., Westberg, K., \& Farrelly, F. (2014). Understanding fan motivation for interacting on social media. Sport Management Review, 17, 455-469. doi: 10.1016/j.smr.2013.11.004

Stronach, M., \& Adair, D. (2009). 'Brave new world' or 'sticky wicket'? Women, management and organizational power in Cricket Australia. Sport in Society, 12, 910-932. doi: 10.1080/17430430903053174 Thibault, L., \& Babiak, K. (2005). Organisational changes in Canada's sport system: Toward an athletecentred approach. European Sport Management Quarterly, 5, 105-132. doi: 10.1080/16184740500188623 
Thompson, A. J., Martin, A. J., Gee, S., \& Eagleman, A. N. (2014). Examining the development of a social media strategy for a national sport organization: A case study of Tennis New Zealand. Journal of Applied Sport Management, 6, 42-63.

Tushman, M. L., \& O’Reilly, C. A. (1996). The ambidextrous organizations: Managing evolutionary and revolutionary change. California Management Review, 38, 8-30. doi: $10.2307 / 41165852$

Wang, Y., \& Zhou, S. (2015). How do sports organizations use social media to build relationships? A content analysis of NBA clubs' Twitter use. International Journal of Sport Communication, 8, 133-148. doi: 10.1123/ijsc.2014-0083

Waters, R. D., Burke, K. A., Jackson, Z. H., \& Buning, J. D. (2011). Using stewardship to cultivate fandom online: Comparing how National Football League teams use their web sites and Facebook to engage their fans. International Journal of Sport Communication, 4, 163-177.

Wells, K. J. (2016). Work-family initiatives from an organizational change lens. In T. D. Allen \& L. T. Eby (Eds.), The Oxford handbook of work and family (pp. 215-228). New York, NY:

Oxford University Press.

Welty Peachey, J., \& Bruening, J. (2011). An examination of environmental factors driving change and stakeholder responses in a Football Championships Subdivision athletic department. Sport Management Review,
14, 202-219. doi:

10.1016/j.smr.2010.03.002

Williams, J., \& Chinn, S. J. (2010). Meeting relationship-marketing goals through social media: A conceptual model for sport marketers. International Journal of Sport Communication, 3, 422-437.

Yi, S., Knudsen, T., \& Becker, M. C. (2016). Inertia in routines: A hidden source of organizational variation.

Organization Science, 27, 782-800. doi: 10.1287/orsc.2016.1059

Ybema, S., Thomas, R., \& Hardy, C. (2016). Organizational change and resistance: An identity perspective. In D. Courpasson, \& S. Vallas (Eds.), The $S A G E$ bandbook of resistance (pp. 386404). Thousand Oaks, CA: SAGE.

Zakus, D. H., \& Skinner, J. (2008). Modelling organizational change in the International Olympic Committee. European Sport Management Quarterly, 8, 421-442. doi: $10.1080 / 16184740802461660$ 


\section{Table and Appendix}

Table 1

Organizational Characteristics

\begin{tabular}{|c|c|c|c|c|c|}
\hline Organization & $\begin{array}{l}\text { Interviewer } \\
\text { Pseudonym }\end{array}$ & Season & $\begin{array}{c}\text { Social } \\
\text { media } \\
\text { presence }^{a}\end{array}$ & $\begin{array}{c}\text { Twitter } \\
\text { followers }\end{array}$ & $\begin{array}{c}\text { Facebook } \\
\text { likes }^{\text {b }}\end{array}$ \\
\hline Tennis Canada & Linda & $\mathrm{S}$ & High & 29,418 & 37,964 \\
\hline Curling Canada & Anthony & W & High & 27,470 & 52,365 \\
\hline Softball Canada & Jim & S & Mid-high & 8,827 & 7,116 \\
\hline $\begin{array}{l}\text { Canada } \\
\text { Snowboard }\end{array}$ & Bill & W & Mid-high & 7,438 & 13,223 \\
\hline $\begin{array}{l}\text { Canada } \\
\text { Freestyle Ski }\end{array}$ & Jade & W & Mid-high & 5,602 & 10,677 \\
\hline Sail Canada & Carla & S & Mid-low & 3,626 & 2,885 \\
\hline $\begin{array}{l}\text { Bobsleigh } \\
\text { Canada }\end{array}$ & Corey & W & Mid-low & 2,834 & 1,568 \\
\hline Archery Canada & Andrew & $S$ & Mid-low & 2,570 & 2,481 \\
\hline Luge Canada & Terrence & W & Low & 1,417 & 1,106 \\
\hline Fencing Canada & Cassandra & $\mathrm{S}$ & Low & 996 & 4,245 \\
\hline
\end{tabular}

a. Based on Naraine and Parent (2016)

b. As of November 15, 2016. 


\section{Appendix A}

\section{General information}

$$
\text { Interview Guide (without prompt questions) }
$$

1. What is your role within the national sport organization?

2. How long have you served in this role? Have you performed other duties within the organization?

3. How does your role allow you to communicate to others within the organization and external to the organization?

National Sport Organization design

1. What is the primary function of your organization? Who does it serve? Why does it exist?

2. What is the mission of the organization?

3. What are the organization's vision and values?

4. How many staff work in the organization?

Social media

1. How would you describe the social media presence of your organization compared to traditional modes of communication?

2. How does a social media presence align with your organization's mission, vision, and values (if at all)? Do you use social media to advance these at all?

3. What is the greatest strength and challenge to your organization in using social media?

Isomorphism and credibility 
1. Are sport organizations more credible if they have social media platforms? Less credible if they don't?

2. How would you compare your organization's use of social media compared to other national sport organizations in Canada?

3. Do you mimic or adopt practices of other NSOs with respect to social media? If so, which ones and why? If not, why?

4. How does your organization differ from other similar organizations with its social media?

Future

1. Will social media become more important, less important, or remain the same for your organization? Why?

2. How does the emergence of new, salient social media platforms affect your organization?

3. Does the emergence of new social media trends or platforms affect your organization's strategy? Why?

4. Is there more your organization can do to connect to stakeholders via social media? If so, what?

Final question

1. Is there anything else you would like to mention in regards to what we've discussed today? 